\title{
Far Infrared Radiation Property of Elbaite/Alumina Composite Materials
}

\author{
Qi Lu ${ }^{1, *}$, Bowen $\mathrm{Li}^{2}$, Huan Zhang ${ }^{1}$ \\ ${ }^{1}$ China University of Geosciences, Beijing, 100083, China \\ ${ }^{2}$ Michigan Technological University, Houghton, MI 49931, U.S.A
}

\begin{abstract}
Far infrared materials have been prepared by precipitation method using natural elbaite powder as raw materials, which belongs to tourmaline group. The chemical formula of elbaite is $\mathrm{Na}(\mathrm{Al}, \mathrm{Li})_{3} \mathrm{Al}_{6} \mathrm{~B}_{3} \mathrm{Si}_{6} \mathrm{O}_{27}(\mathrm{O}, \mathrm{OH}, \mathrm{F})_{4}$. X-ray powder diffraction (XRD) shows that elbaite and alumina in composite material has good crystal form. In addition, XRD results indicate the formation of alumina crystallites show that alumina powder exists as nano-meter particles on the surface of elbaite powder. It can be calculated the particles diameter of $\mathrm{Al}_{2} \mathrm{O}_{3}$ is $47.86 \mathrm{~nm}$. The maximum infrared radiation rate of tourmaline/alumina composite materials is 0.89 when the ratio of alumina in elbaite powder is $20 \%$. The infrared radiation rate has been increased by 0.03 , compared with single elbaite. It shows that the infrared radiation rate of the composite materials is higher than any of a single component. Two reasons are attributed to the improve of the rate of far infrared radiation: alumina powder exists as nano-meter particles and different materials will increase the absorption peak and the vibration intensity in FTIR spectra.
\end{abstract}

\section{Introduction}

Elbaite is one kind of tourmaline group, which is a borosilicate mineral that belongs to the trigonal space group of R3m-C3. Tourmaline has complex composition and its crystal chemical formula is $\mathrm{XY}_{3} \mathrm{Z}_{6}\left[\mathrm{Si}_{6} \mathrm{O}_{18}\right]\left[\mathrm{BO}_{3}\right]_{3}$ $(\mathrm{O}, \mathrm{OH}, \mathrm{F})_{4}$. X position is occupied not only by $\mathrm{Na}^{+}$or $\mathrm{Ca}^{2+}$, but also by $\mathrm{Na}^{+}, \mathrm{K}^{+}$, and sometimes there are vacancies (which can form alkali free tourmaline). $\mathrm{Y}$ position is mainly occupied by $\mathrm{Fe}^{2+}, \mathrm{Fe}^{3+}, \mathrm{Mg}^{2+}, \mathrm{Mn}^{2+}$ and $\left(\mathrm{Al}^{3+}+\mathrm{Li}^{+}\right)$. $\mathrm{Z}$ position is mainly occupied by $\mathrm{Al}^{3+}$, as well as $\mathrm{Fe}^{2+}, \mathrm{Mn}^{3+}, \mathrm{Li}^{+}, \mathrm{Ti}^{4+}$, etc. Replacement of $\mathrm{X}, \mathrm{Y}, \mathrm{Z}$ is very common in tourmaline group[1]. Because of its spontaneous polarity, tourmaline can generate electrode under natural condition. It has many kinds of properties which can be applied in environmental protection and human health-care, such as generating far infrared radiation, releasing negative ions and electromagnetic shielding [2-5].

Although the composition of tourmaline is various, all kinds of mineral crystals have piezoelectric and pyroelectric properties. The difference of the composition and content of various metal ions leads to the difference of spontaneous polarization and pyroelectric properties. Among the tourmaline group, the most common mineral species are dravite, iron tourmaline, and elbaite. Yang Ruzeng through testing the infrared radiation of different kinds of tourmaline, he thinks that the main reasons for its strong infrared radiation characteristics are the crystal defects of black tourmaline[6-8]. Iron has a negative effect with the pyroelectric properties, and the more iron content, the lower the pyroelectric properties. Because of containing few Fe element of lithium, it can be inferred that pyroelectric property of elbaite is higher than that of dravite and iron tourmaline. Therefore, the performance of far infrared radiation of elbaite should be much higher than that of $\mathrm{Mg}-\mathrm{Fe}$ tourmaline group.

In order to enhance the far infrared radiation, elbaite/alumina composite materials are prepared in this paper. Alumina powder has high far infrared radiation rate at room temperature which is more than 0.90 , but it is low (no more than 0.80 ) in the band of $5-15 \mu \mathrm{m}$. Therefore, the elbaite/alumina composite powders will make the absorption peak in the far infrared position, and it will enhance the rate of far infrared radiation in the low band among $5-15 \mu \mathrm{m}$, which is very important to human health.

\section{Experimental procedure}

\subsection{Preparation of samples}

In this research, the far infrared materials were prepared by chemical precipitation method and elbaite powder $(\mathrm{D} 50=6 \mu \mathrm{m})$. The main raw materials of nano-meter alumina are selected as follows: $\mathrm{Al}\left(\mathrm{NO}_{3}\right)_{3} \cdot 9 \mathrm{H}_{2} \mathrm{O}$ (analytical grade), ammonia solution, deionized water, ethanol etc. the nano-meter particles of alumina powder can be made by chemical precipitation. Chemical compositions of elbaite samples from Fuping, Henan province, were analysed by X-ray fluorescence spectrometry (Philips PW2404) as showed in Table 1.

\footnotetext{
*Corresponding author: luqi@cugb.edu.cn
} 
Table 1. Chemical Component of Elbaite Samples

\begin{tabular}{cccccccccccccc}
\hline $\mathrm{SiO}_{2}$ & $\mathrm{Al}_{2} \mathrm{O}_{3}$ & $\mathrm{TiO}_{2}$ & $\mathrm{Fe}_{2} \mathrm{O}_{3}$ & $\mathrm{FeO}$ & $\mathrm{MnO}$ & $\mathrm{MgO}$ & $\mathrm{CaO}$ & $\mathrm{Na}_{2} \mathrm{O}$ & $\mathrm{K}_{2} \mathrm{O}$ & $\mathrm{P}_{2} \mathrm{O}_{5}$ & $\mathrm{~F}$ & Loss & Total \\
\hline 43.64 & 42.73 & - & 0.031 & - & 0.43 & - & 0.72 & 2.17 & 0.04 & 0.05 & 4.09 & 4.70 & 98.601 \\
\hline
\end{tabular}

By chemical precipitation, precursor $\mathrm{Al}(\mathrm{OH})_{3}$ was formed. Controlling the reaction conditions and stirring continuously, the precursor $\mathrm{Al}(\mathrm{OH})_{3}$ was evenly coated on surfaces of tourmaline particles and formed elbaite/ $\mathrm{Al}(\mathrm{OH})_{3}$ composite particles. Then the obtained composite particles were calcined at desired temperature, and the elbaite $/ \mathrm{A}_{2} \mathrm{O}_{3}$ composite materials were prepared. The ratio of $\mathrm{Al}_{2} \mathrm{O}_{3}$ added to elbaite powder were selected at $0,10 \%, 20 \%, 30 \%$, noted as $\mathrm{HN}-0, \mathrm{HN}-1$, $\mathrm{HN}-2, \mathrm{HN}-3$. Ultrasonic dispersion was used to make tourmaline powder dispersed in the solution. Then, magnetic stirring was used for 30 minutes at room temperature to keep the suspension uniformly dispersed. Finally, in order to transfer to a ceramic crucible, the composite materials were sintered at $800^{\circ} \mathrm{C}$ for 3 hours, and then cooled to room temperature for further test.

Table 2. Compositions of the Composite Materials

\begin{tabular}{cccccc}
\hline Compositions & C-HN-0 & C-HN-1 & C-HN-2 & C-HN-3 & C-HN-4 \\
\hline Elbaite & 100 & 90 & 80 & 70 & 60 \\
$\mathrm{~A}_{2} \mathrm{O}_{3}$ & 0 & 10 & 20 & 30 & 40 \\
\hline
\end{tabular}

\subsection{Characterization and property test}

Test instruments used for this study include 5DX Fourier Transform Infrared Spectrometer and JD-1 blackbody furnace. The effective infrared rate of blackbody furnace is more than 0.998 , and the integral value ratio of the radiation spectra is between $5 \mu \mathrm{m}$ and $15 \mu \mathrm{m}$. The far infrared rate is the ratio of radiant emittance of an object to that of a blackbody.

X-ray diffraction (XRD) was used to determine the effects of tourmaline content and preparation conditions to infrared emissivity and other properties. The XRD instrument type was D/Max-IIA, and the operational parameters for the analysis were $\mathrm{Cu}$ target, scanning range $5^{\circ}-80^{\circ}$, scanning speed $4^{\circ} / \mathrm{min}$.

In order to analyse the form of composite materials, FTIR was used to distinguish the composite materials with different tourmaline $/ \mathrm{Al}_{2} \mathrm{O}_{3}$ ratio.

The test conditions: working voltage $220-240 \mathrm{~V}$, resolution $4 \mathrm{~cm}^{-1}$, scan range $4000-400 \mathrm{~cm}^{-1}$. The test was completed in Beijing institute of mining and metallurgy.

\section{Results and discussion}

\subsection{Far-infrared emission property}

The samples C-HN-1, C-HN-2, and C-HN-3 have identical raw materials used for preparation but different $\mathrm{E} / \mathrm{A}$ ratios in the composite materials. The results are shown in Table 3. From Table3, it can be seen that the infrared radiation rates of the samples vary greatly. The sample of C-HN-2 has the highest infrared radiation rate, which reached 0.89 . Compared with the single tourmaline materials, the infrared radiation rate of composite materials has increased by 0.03 , and increased by 0.04 comparing to nano-meter alumina particles. Therefore, the composite materials have a higher infrared radiation rate compared with any of single powder.

Far infrared emission rate of a composite material depends on the vibration peak of particle size, number, intensity, and interactive effect of any single component in the composite materials. For elbaite/alumina composite materials, the infrared emission rate depends on the infrared vibration of elbaite and alumina individually and their interactive effectiveness.

Tab.3 Infrared Radiation Rate of Composite Materials with Different Ratio（\%)

\begin{tabular}{cccc}
\hline Samples $(\mu \mathrm{m})$ & Ratio & infrared radiation & wavelength range \\
\hline $\mathrm{C}-\mathrm{HN}-0$ & - & 0.86 & $5-15$ \\
$\mathrm{C}-\mathrm{HN}-1$ & 10 & 0.86 & $5-15$ \\
$\mathrm{C}-\mathrm{HN}-2$ & 20 & 0.89 & $5-15$ \\
$\mathrm{C}-\mathrm{HN}-3$ & 30 & 0.87 & $5-15$ \\
$\mathrm{Al}_{2} \mathrm{O}_{3}$ & - & 0.85 & $5-15$ \\
\hline
\end{tabular}

\subsection{Crystal Structure (XRD)}

XRD patterns of composite materials with different ratio of elbaite and alumina (C-HN-1, C-HN-2, C-HN-3) are show in Fig.1.

In addition to the diffraction peaks of elbaite $(\mathrm{E})$, the diffraction peak of $\mathrm{Al}_{2} \mathrm{O}_{3}$ typical graph (A) is strong and sharp in fig. 1 , and it indicates that $\mathrm{Al}_{2} \mathrm{O}_{3}$ powder has good crystal integrity in the elbaite $/ \mathrm{Al}_{2} \mathrm{O}_{3}$ composite materials.

Through the comparison of C-HN-1, C-HN-2, C-HN3 , it can be seen that with increasing of $\mathrm{Al} 2 \mathrm{O} 3$ content, the diffraction peak of $\mathrm{Al}_{2} \mathrm{O}_{3}$ in the composite powder is more and more obvious, and the spectral peak of elbaite becomes more and more weak.

The results of XRD can be used to measure the particles size. When the grain size is less than $100 \mathrm{~nm}$, the $\mathrm{X}$ ray diffraction peak changes with the crystal size 
and the average particles diameter can be calculated by Scherrer formula[9-11]:

$$
D=K \lambda(\beta \cos \theta H K L)
$$

Taking sample $\mathrm{C}-\mathrm{HN}-1$ as an example, the approximate particles size of $\mathrm{Al}_{2} \mathrm{O}_{3}$ can be calculated according to the data of XRD with the sample C-HN-1. $\mathrm{D}$ (HKL) in the formula (1) is the average particles size of crystal surface along the normal direction of the value, $\mathrm{K}$ is constant, $\mathrm{K}=0.89 ; \mathrm{X}$ ray wavelength $\lambda$ $=0.15406 \mathrm{~nm}, 2 \theta=36.10^{\circ}, \beta=0.625-0.214=0.411^{\circ}$, it can be calculated that the average particles diameter of $\mathrm{Al} 2 \mathrm{O} 3$ is $47.86 \mathrm{~nm}$, which has reached nano-meter.

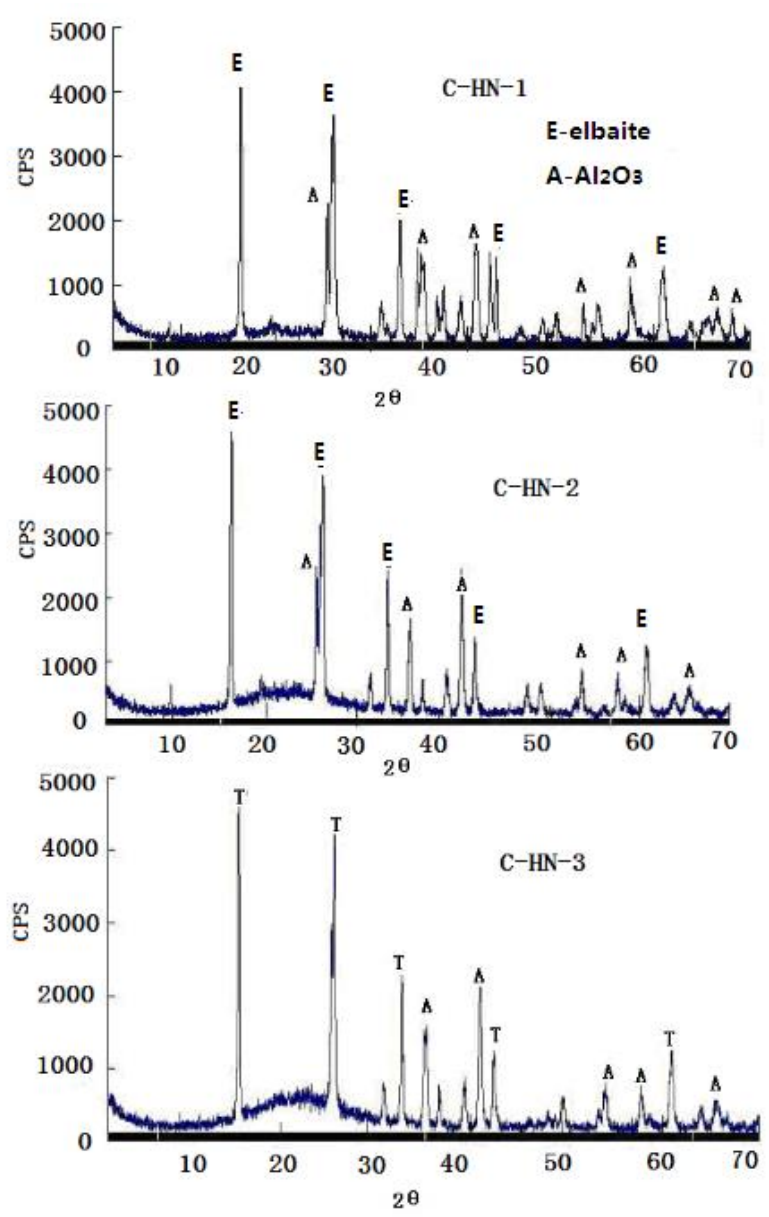

Fig.1. XRD Patterns of the Composites in Different elbaite /alumina Ratio

\subsection{FTIR analysis}

Three samples as mentioned above, C-HN-1, C-HN-2 and $\mathrm{C}-\mathrm{HN}-3$ were analyzed with FTIR under test conditions: working voltage $220-240 \mathrm{~V}$, resolution $4 \mathrm{~cm}^{-1}$, scan range $4000-400 \mathrm{~cm}^{-1}$. The FTIR patterns are shown in Fig.2.

In Fig.3, the composite materials show the typical infrared spectrums of both tourmaline and $\mathrm{Al}_{2} \mathrm{O}_{3}$ respectively. Because of the small particle size, the infrared spectrum of tourmaline grains shifted to a certain extent, and the absorption peak become widen than the regular FTIR patterns [12-15].

Nano scale $\mathrm{Al}_{2} \mathrm{O}_{3}$ powder has two characteristic peaks on the infrared spectra. One is a broad absorption band in the range of $400-1000 \mathrm{~cm}^{-1}$, and another is in the vicinity of the $1380 \mathrm{~cm}^{-1}$ due to the phonon vibration of nanoscale $\mathrm{Al}_{2} \mathrm{O}_{3}$ particles. Both characteristic peaks of nanoscale $\mathrm{Al}_{2} \mathrm{O}_{3}$ particles appeared in Fig.3. In this study, through strict control of reaction conditions, nanoscale $\mathrm{Al}_{2} \mathrm{O}_{3}$ particles have high specific surface area, which will form a large number of dangling bonds on the surface of particles. As a result, the infrared vibration peaks of $\mathrm{Al}_{2} \mathrm{O}_{3}$ particles become strengthened.

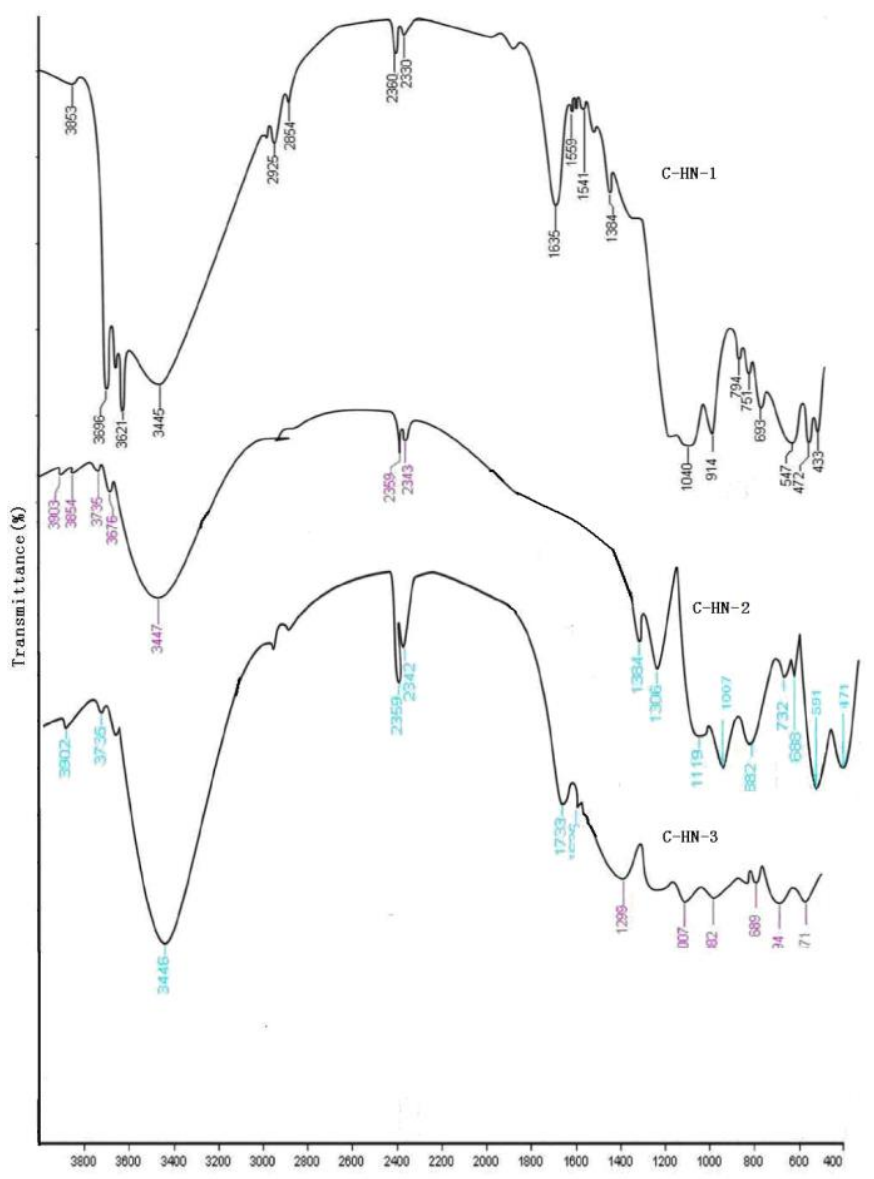

Fig. 2. FTIR Patterns of the Products with Different T/A Ratio

\section{Conclusions}

Select elbaite produced in Henan as the main raw material, and have obtained elbaite $/ \mathrm{Al}_{2} \mathrm{O}_{3}$ composite materials by chemical precipitation method. The composite particles are analyzed by XRD and FTIR. Moreover, the far infrared radiation rates of composite materials are tested. The main conclusions are as follows: 1. Elbaite $/ \mathrm{Al}_{2} \mathrm{O}_{3}$ composite materials are obtained successfully by chemical precipitation method. XRD and SEM analysis show that tourmaline and $\mathrm{Al}_{2} \mathrm{O}_{3}$ both have good crystal forms in the composite materials. The average size of $\mathrm{Al}_{2} \mathrm{O}_{3}$ particles calculated by using 
Scherrer equation is $47.86 \mathrm{~nm}$. It is also proved by FTIR

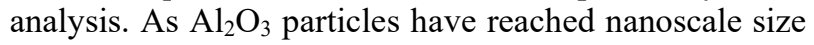
and it will enhance the performance of the tourmaline/ $\mathrm{Al}_{2} \mathrm{O}_{3}$ composite materials.

2. Compared with the different ratio of tourmaline, the sample of $\mathrm{C}-\mathrm{HN}-2$ has the highest infrared radiation rate, which has reached 0.89 . Compared with the single tourmaline material, the infrared radiation rate of composite materials has increased by 0.03 , and increased by 0.04 compared with single nanoscale $\mathrm{Al}_{2} \mathrm{O}_{3}$ material. Therefore, the composite materials have a high infrared radiation rate. It has achieved the desired effect in the experiments. This is also consistent with the result of FTIR test.

3. The infrared radiation rate of the tourmaline $/ \mathrm{Al}_{2} \mathrm{O}_{3}$ composite materials is higher than any one single material. The reasons are as follows: different materials will increase the absorption peak and the vibration intensity in FTIR spectra. Furthermore, with the number of the composite materials increasing, the different components will interact between particles, which will affect the symmetry of the crystal structure. Therefore, the infrared radiation rate of the composite materials is higher than any one single material.

\section{Acknowledgements}

This project is supported by "the Fundamental Research funds for the Central Universities" under Grant No.2011YYL138.

\section{References}

1. Nakamura T, Kubo T. J. Ferroelectrics, 137(1992)

2. $\mathrm{Hu}$, Zhenfeng, Sun, Chuanyao. Procedia Environmental Sciences, 31( 2016)

3. Na Liu, Hang Wang, Chih-Huang. Arabian Journal of Chemistry.11(2018)

4. Xu, H.Y., Prasad, M. and Liu, Y. Journal of Hazardous Materials, 165(2009)

5. Jiang, K., Sun, T.H., Sun, L.N. and Li, H.B. Journal of Environmental Sciences, 18(2006)

6. Feng yanwen. Applied Mechanics and Materials 423-426(2013)

7. Qi Lu, Feng Bai, Ni Wang. Applied Mechanics and Materials, 490-491(2014)

8. Yingmo Hu. Open Journal of Composite Materials, 148-156(2014)

9. H. Takashima, T. Suclyama. Bulletin of Society of Japan, 23( 1988)

10. Frank C. Hawthorne and Darrell J. Henry. Europe .J. Mineral, 11(1999)

11. Fuat Yavuz, Vural Yavuz, Ahmet Sasmaz. Computers Geosciences, 32(2006)

12. Hayder Abbas Sallal, Alaa A. Abdul-Hamead, Farhad Mohammad Othman. Defence Technology 16 (2020)
13. H. Gleiter, Nanocrystalline materials. Prog.in Mater.Sci., ,33(1989)

14. Castaneda C,Oliveira E F, Gomes N, and Pedrosa Soares A C. American Mineralogist, 85 (2000)

15. P.S.R. Prasad. Study of structural disorder in natural tourmalines by infrared spectroscopy. Gondwana Research, 8(2005) 